\title{
A Conceptual Model of Job Burnout and Work Social Support
}

\author{
S. M. D. Y. Jayarathna \\ Department of Human Resource Management, Faculty of Commerce and \\ Management Studies, University of Kelaniya, Sri Lanka \\ dinethiyasodara@kln.ac.lk \\ (D) https://orcid.org/0000-0002-5964-4914
}

\begin{abstract}
This paper aims to develop a model on job burnout with the work social support and employee engagement. The model argues a mediating of employee engagement in explaining the influence of work social support on job burnout. Further, it also suggest the importance of identification of job burnout not only in the service jobs but also in out of service sector. The paper proposes the relationships between perceived supervisor and coworker support with burnout, and the mediating effect of employee engagement on the direct relationships, by getting the support from conservation of resource theory and job-demand resource theory.
\end{abstract}

Keywords: Job Burnout, Perceived supervisor Support, Perceived Coworker Support, Employee Engagement, Conservation of Resource Theory, Job Demand-Resource Theory

\section{Introduction}

Human beings having a special relationship with their work and as individuals they face difficulties whenever this relationship goes wrong. Further, individuals are exposed to various job demands in terms of administrative difficulties, emotional conflict, role conflict, physical and psychological energy which get reduced due to the job (Crawford, LePine, \& Rich, 2010; Demerouti, Bakker, Nachreiner, \& Schaufeli, 2001; Schaufeli, Bakker, \& van Rhenen, 2009). This phenomenon has been recognized as a significant one in the present era. Both practitioners and social observers identified burnout as a social problem, where it draws the focus of academics and researchers for a systematic identification of the phenomenon (Maslach, Schaufeli, \& Leiter, 2001).

Burnout is a representation of a symbol, which commonly signify a state of mental tiredness. Originally burnout was considered to happen in the human services where people engaged with the job includes interactions with people 
(Maslach \& Goldberg, 1998; Maslach \& Schaufeli, 1993). Nevertheless, gradually burnout has been identified outside of service jobs (Maslach \& Leiter, 1997) where employees who are engaged in operations, production and administrative activities, experience burnout at work. Furthermore, the original version of Maslach Burnout Inventory developed by Maslach and Jackson (1986) was adopted outside the service jobs, which confirmed that burnout, exist outside of service jobs.

Though the phenomenon of burnout has been identified by previous scholars, it was rarely acknowledged or discussed in open forums. For some professions it was an offensive topic where people was not admitting the fact that professionals may act unprofessionally at times in work (Schaufeli, Maslach, \& Marek 1993). Thus, it is significant to investigate job burnout focusing on specific professions to examine the behavior of professionals in times of experiencing job burnout.

Given the attention of increasing job burnout, organizations look for determinants, which reduces the unprofessional behavior at work in terms of increasing the job performance. Thus, many of the studies have emphasized that job burnout can be alleviated by enhancing coping strategies (social support) (Cordes and Dougherty, 1993; Demerouti et al., 2001; Schaufeli and Bakker, 2004). However, little research studies have been conducted to identify the influence of work social support on job burnout, significantly many researchers neglected the coworker support. Further, Thanacoody, Bartram and Casimir (2009) suggested that it is needed to explore the social support mechanisms and their effect on job burnout. Moreover, employee engagement is an area that less investigated with work social support, which needed the attention of academics. The present study developed a model with work social support (perceived supervisor support and perceived coworker support), job burnout and employee engagement to fill this knowledge gap. Furthermore, less studies have been conducted in the non-western context, (Muhammad, \& Hamdy, 2005) and out of the service jobs, which suggesting a new study.

\section{Burnout}

Burnout is defined as a psychological syndrome characterized by emotional exhaustion, depersonalization and reduction of personal accomplishments 
(Maslach \& Jackson, 1981, 1986). Emotional exhaustion is the feeling of being emotionally overextended and depletion of emotional resources. It indicates the fatigue and tiredness of an individual while exhaustion component signifies the basic stress dimension of burnout. Depersonalization is negative, insensitive and excessively detached from other people and work attitudes, where reduced personal accomplishments depicted through deterioration of one's competence and effective achievement of their work (Maslach \& Goldberg, 1998; Schaufeli \& Bakker, 2004). It is noted that exhaustion always described in terms of loss of energy, depletion, and fatigue. Depersonalization through negative attitudes towards clients, loss of optimistic behavior and increase the irritability towards anything. Further, reduction of personal accomplishment is described as reduced productivity, capability with less morale and inability to cope with work (Maslach et al., 2001).

When as individual experience burnout, it increases absenteeism, turnover intentions and actual turnover. Further, it reduces job performance, job involvement, job satisfaction, commitment to job and organization both (Bakker \& Demerouti, 2007; Burke \& Richardsen, 1993; Maslach et al., 2001). Moreover, Burke and Greenglass (2001) stated that when people experience burnout create negative effect on their coworkers by creating interpersonal conflicts and by disturbing job tasks and duties. Hence, burnout can be transmittable, spread through informal interactions on the job, and create negative spillover effect on people's home life creating work-life imbalance. Moreover, Maslach et al. (2001) have identified several job characteristics that lead to burnout. Mostly, work overload and time pressure strongly and consistently associated with burnout, especially with exhaustion dimension. Further, role conflict, role ambiguity, higher job demands with less resources lead occurrence of burnout.

\section{Employee Engagement}

Employee engagement represents the degree of involvement, participation and satisfaction to the organization and job (Nahrgang, Morgeson, \& Hofmann, 2011). Schaufeli, Salanova, Gonza'lez-Roma', and Bakker (2002, p. 74) have defined engagement as a positive, fulfilling, work-related state of mind characterized by vigor, dedication, and absorption. Vigor is high levels of energy, mental flexibility, and willingness in investing effort in work. 
Dedication is defined as enthusiasm, inspiration, pride and challenge about the work. Absorption is being fully concentrated and happy with the work (Schaufeli \& Bakker, 2004). Thus, people who are engaged at work are active, generate positive emotions, and possess problem solving coping styles that enhance the willingness to invest energy in efforts to meet the job demands (Crawford, LePine \& Rich, 2010; Demerouti, Bakker, Nachreiner \& Schaufeli, 2001).

Employee engagement is assumes as the positive side of burnout. Maslach and Leiter (1997) stated that burnout is the direct opposite of dimensions of employee engagement. They discussed that energy, involvement and efficacy are the direct opposites of the three dimensions of burnout (exhaustion, depersonalization and reduction of personal accomplishment). Accordingly, their view emphasize that burnout is an attrition of engagement where energy generated while engaging in job turns in to exhaustion, involvement in to depersonalization and efficacy in to reduction of personal accomplishment (Schaufeli \& Bakker, 2004). Thus, it emphasized that when employees are engaged in their job, leading a reduction of burnout as employee engagement act as the opposite of job burnout.

In the present era, most of the researchers have been started to focus their interest of employee engagement. Several researchers have stated that employee engagement predicts number of employee outcomes, organizational accomplishments and financial performance in terms of shareholder wealth (Baumruk, 2004; Harter, Schmidt, \& Hayes 2002). This claimed since employee engagement include cognitive, emotional and a behavioral components which positively associate with employee role performance. Moreover, employees are engaged when they are provided with workable workload, meaningful work with autonomy, appropriate recognition and reward, a supportive work environment, supportive coworkers and supervisors, and organizational justice and fairness (Saks, 2006). Hence, individuals are more likely to engage themselves with the job in an environment where organization provides these resources.

\section{Perceived Supervisor Support}

Supervisor support is "a social resource and transaction, which provides necessary resources to people in need of help" (Marin \& Garcia-Ramirez, 
2005, p. 97). Perceived supervisor support is the perception of employees that their supervisor values their contribution and cares about their well-being (Eisenberger, Stinglhamber, Vandenberghe, Sucharski, \& Rhoades, 2002). Employees face difficult situation while working, such work load, role conflict, and less autonomy which hard to manage alone. Thus, employees need the support in managing which can be expected from the work social support characterize by supervisor and coworker (Cohen \& Wills, 1985; Kossek, Pichler, Bodner, \& Hammer, 2011; Mayo, Sanchez, Pastor, \& Rodriguez, 2012; Russo, Shteigman, \& Carmeli, 2016).

Accordingly, several studies have found out that perceived supervisor support aid in decreasing work family conflict, psychological strain, turnover, voluntary turnover and increase job satisfaction, family satisfaction, job performance, productivity and organizational performance (Dysvik \& Kuvaas, 2013; Eisenberger et al., 2002; Karatepe, 2010; Kuvaas \& Dysvik, 2010; O’Driscoll \& Beehr, 1994; Rhoades \& Eisenberger, 2002; Hsu, 2011). Moreover, several studies have been found the relationship between supervisor support and well-being of employees, and it was found that supervisor support decreases both stress and emotional exhaustion (Greenglass, Burke, \& Konarski, 1997). In addition, supervisor support reduces burnout and increase the service performance of employees in call centers (Singh, 2000) and make it easier for employees to enhance their knowledge. Thus, supervisor support is considered as important factor in development of employees (Ellinger, Ellinger \& Keller, 2003) by providing work knowledge to fulfill the job demands (Schaufeli \& Bakker, 2004) in a satisfactory manner without experiencing burnout.

\section{Perceived Coworker Support}

Fisher (1985, p. 40) defined coworker support as "the number and quality of friendships or caring relationships, which provide either emotional reassurance, needed information, or instrumental aid in dealing with stressful situations". Almost all the situations, supportive coworkers are significant in prompting employee morale, completing assigned work-related tasks, and create an environment where employees share their creative ideas as well as mistakes without any obstruction (Joiner, 2007; Susskind, Kacmar, \& Borchgrevink 2003). Employees are able to access more job resources when they perceive high coworker support that allow them to manage the stress at 
work (Guchait, Paşamehmetoğlu, \& Dawson, 2014). Furthermore, recent researchers have argued that coworker support is more than giving work related information, but proving more emotional support such as love, care and empathy (Rousseau, Salek, Aubé, \& Morin, 2009), which will aid in reducing experiencing burnout at work. Prior research has asserted that coworker support reduces strain experienced in the job (Beehr, Farmer, Glazer, Gudanowski, \& Nair, 2003; Beehr, Jex, Stacy, \& Murray, 2000)

Support from coworker enhances job satisfaction and reduce turnover intentions (Alexander, Lichtenstein, Oh, \& Ullman, 1998; Dysvik \& Kuvaas, 2013; Griffeth, Hom \& Gaertner, 2000; Lichtenstein, Alexander, McCarthy \& Wells, 2004; Ng \& Sorensen, 2008) and having positive relations with coworkers enhance employee well-being (Ducharme, Knudsen, \& Roman, 2007). Further researchers have found out that coworker support is positively associated with job involvement, work engagement, job performance and organizational commitment (Bakker \& Demerouti, 2007; Rich, LePine, \& Crawford, 2010; Chiaburu \& Harrison, 2008; Karatepe, Keshavarz, \& Nejati, 2010). It was identified that occurrence of harmful work events due to high job demands can be reduced through coworker support (Turner, Chmiel, Hershcovis, \& Walls, 2010).

\section{Job Demand-Resource Model}

Bakker, Demerouti and Sanz-Vergel (2014) describe two categories of job characteristics/working conditions, which exist in work environment; job demands and resources using Job Demands-Resources (JD-R) theory. Job demands include physical, psychological, social and organizational aspects of a job. For example high work pressure, unfavorable working environment, and emotional demands. (Bakker \& Demerouti, 2007; Demerouti et al., 2001).

Job demands require substantial energy and they can be challenging with the higher workload and difficult tasks that obstruct attaining the organizational goals. Thus, higher job demands leads to energy depletion and exhaust the employees ( $\mathrm{Li}$, Jiang, Yao, \& Li, 2013) where reduce the positive wellbeing of the employees. Job resources include social, psychological, physiological or environmental factors that support employees to achieve work goals, and reduce higher job demands. Social support, which considered as a job 
resource can be derived through supervisors and coworkers (Bakker \& Demerouti, 2007; Demerouti et al., 2001). Those interpersonal and social relations create a supportive working environment that individuals are creating a capability of managing uncomfortable circumstances such as stress and burnout.

Job resources become the motivational factors in a job where supports in achieving organizational goals inculcating the job demands in a positive manner (Demerouti et al., 2001). Moreover, supervisor support and coworker support consistently considered as job resources in the work environment (Crawford et al., 2010; Demerouti et al., 2001; Schaufeli, Bakker, \& Van Rhenen, 2009; McCalister et al., 2006; Nahrgang, Morgeson, \& Hofmann, 2011). Supportive supervisor and coworker provide advice and assist employees to manage the work in a positive manner while create team work environment (Morgeson \& Humphrey, 2006) that generate synergetic effect which ultimately achieve both individual and organizational goals.

As job resources create a motivational process, which lead work engagement. Support from supervisor and coworkers create a supportive environment that allow the employees to achieve the organizational goals fostering learning and growth and at the same time motivating intrinsically. Further, these resources aid in reducing higher job demands and having these job resources help individual to stimulate the personal growth, learning and development while reducing physiological and psychological costs (Demerouti et al., 2001; Schaufeli et al., 2009). Through this it create high employee engagement (Bakker \& Demerouti, 2007; Crawford et al., 2010; Demerouti et al., 2001; Nahrgang, Morgeson, \& Hofmann, 2011) where employees generate dedication, positive energy and willingness of investing their effort to perform the job tasks well.

As the Job demand resource theory states, when supportive working environment is exist which foster through supervisor and coworker support, it create buffering mechanism where employees protect from experiencing burnout. On the basis of this theory, it is suggested that there is negative impact of supervisor and coworker support on burnout. This emphasize that when employees perceived supervisor support and coworker support is exist, it support the employees to reduce experiencing burnout. 


\section{Conservation of Resource Theory}

Conservation of Resource Theory (COR) explains that people try their hard to retain, protect and build resources (objects, conditions, personal characteristics, and energies) and they feel threatened by loss of these valuable resources (Hobfoll, 1989). The threat of losing resources make people stress in three possible ways. When resources are threatened, when resources are actually lost and when there is no gain from invested resources (Alarcon, Edwards \& Menke, 2011) individuals experience stress. Further, COR theory suggest that burnout occurs when values resources are lost, and inadequate to meet demands (Hobfoll, 1989). The major demands from work include role ambiguity, role conflict, stressful events, heavy workload, and work pressure. The resources include social support, which can derive from various sources, job enhancement opportunities, job autonomy, motivational opportunities, and participation in decision making (Burke \& Richardsen, 1993; Cordes \& Dougherty, 1993).

Individuals with larger amount of resources meet demands easily and protect themselves from the strains of resource reduction (Lee \& Ashforth, 1996). In addition, employees perceive that they are highly engaged, when they have sufficient amount of resources to fulfill the job demands and challenges of the job (Childs \& Stoeber, 2010). Consequently, employee engagement creates more resources and invest them in the environment, which ultimately experience positive emotions.

COR theory suggests that when employees are threatened with lack of job resources in terms of supervisor and coworker support, employees experience stress and burnout. Yet, when employees with larger amount of resources enable them to engage in the job well with that sufficient amount of resources. Thus, job resources provide energy, mental flexibility, and full concentration towards the job, which make employees highly, engaged in the job. Hence, engaging in the job allow the employees to build the resources and enhance the energy within the individual. As the COR theory stated that building personal resources that reduce experiencing burnout. 


\section{Conceptual Model and Prepositions}

Getting support from previous literature, the two theories, conservation of resource and job-demands and resources, following preposition are suggested in the present study. Figure 01 shows the model and proposed relationships explaining the impact of work social support and job burnout, and the mediating effect of job burnout.

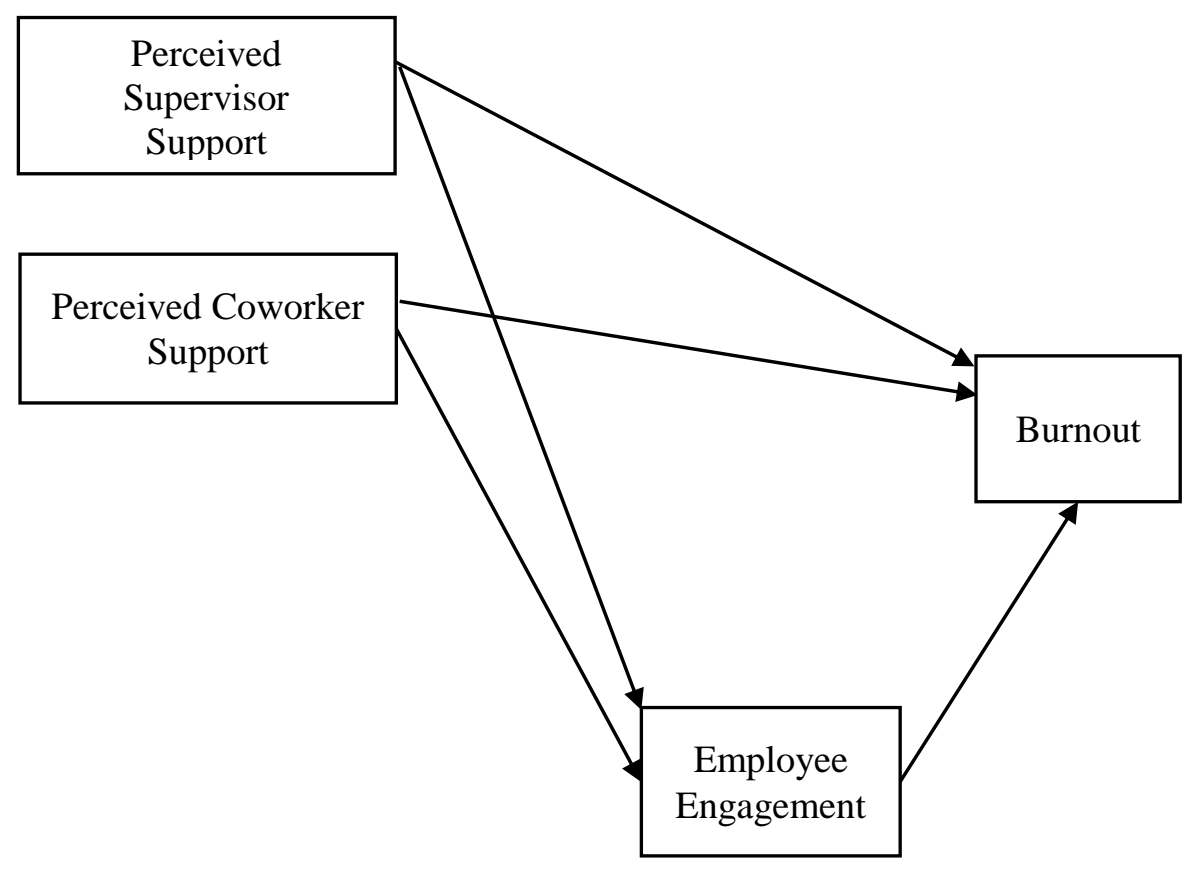

Figure 01: Conceptual Model

Source: Authors Constructed, 2017

Preposition1: There is a negative impact of perceived supervisor support on burnout.

Preposition 2: There is a negative impact of perceived coworker support on burnout.

Preposition 3: There is a mediating effect of employee engagement on the relationship between perceived supervisor support and burnout. 
Preposition 4: There is a mediating effect of employee engagement on the relationship between perceived coworker support and burnout.

\section{Conclusion and Implications}

The significance of job burnout has been widely grabbed the attention of both academics and practitioners. Given consideration on the negative effects of job burnout and substantial need of work resources especially supervisor and coworker support in creating a supportive work environment with having a highly engaged work force, organizations are in a process of exploring ways in developing supportive working conditions with the intention enhancing employee job engagement.

This paper the researcher has developed a conceptual model on job burnout, indicating the relationships with work social support and employee engagement establishing the linkage using conservation of resource theory and job demand-resource theory. The significance of this paper is that it offers logical relationships on which hypotheses were developed on empirical evidence and verify using theories.

Future, researchers will be able to test this model especially in non-service sector to emphasize the existence of job burnout. Moreover, in addition to test the same model researchers can increase the complexity of model by adding more variable as family support, work-life balance, and work over load and flexible work schedules. Further, researchers can use more advance statistical modeling techniques as SEM to test the model, and conduct a comparative study on different industries.

\section{References}

Alarcon, G. M., Edwards, J. M., \& Menke, L. E. (2011). Student burnout and engagement: A test of the conservation of resources theory. The Journal of psychology, 145(3), 211-227.

Albar Marín, M., \& Garcia-Ramirez, M. (2005). Social support and emotional exhaustion among hospital nursing staff. The European Journal of Psychiatry, 19(2), 96-106. 
Alexander, J. A., Lichtenstein, R. L., Oh, H. J., \& Ullman, E. (1998). A causal model of voluntary turnover among nursing personnel in long-term psychiatric settings. Research in Nursing \& Health, 415-427

Bakker, A. B., \& Demerouti, E. (2007). The job demands-resources model: State of the art. Journal of managerial psychology, 22(3), 309-328.

Bakker, A. B., Demerouti, E., \& Sanz-Vergel, A. I. (2014). Burnout and work engagement: The JD-R approach. Annu. Rev. Organ. Psychol. Organ. Behav., 1(1), 389-411.

Baumruk, R. (2004). The missing link: the role of employee engagement in business success.

Beehr, T. A., Farmer, S. J., Glazer, S., Gudanowski, D. M., \& Nair, V. N. (2003). The enigma of social support and occupational stress: source congruence and gender role effects. Journal of occupational health psychology, 8(3), 220231

Beehr, T. A., Jex, S. M., Stacy, B. A., \& Murray, M. A. (2000). Work stressors and coworker support as predictors of individual strain and job performance. Journal of Organizational Behavior, 391-405.

Burke, R. J., \& Greenglass, E. R. (2001). Hospital restructuring, work-family conflict and psychological burnout among nursing staff. Psychology \& health, 16(5), 583-594.

Burke, R. J., \& Greenglass, E. R. (2001). Hospital restructuring, work-family conflict and psychological burnout among nursing staff. Psychology \& health, 16(5), 583-594.

Chiaburu, D. S., \& Harrison, D. A. (2008). Do coworkers make the place? Conceptual synthesis and meta-analysis of lateral social influences in organizations. Journal of Applied Psychology, 93(5), 1082-1103.

Childs, J. H., \& Stoeber, J. (2010). Self-oriented, other-oriented, and socially prescribed perfectionism in employees: Relationships with burnout and engagement. Journal of Workplace Behavioral Health, 25(4), 269-281.

Cohen, S., \& Wills, T. A. (1985). Stress, social support, and the buffering hypothesis. Psychological bulletin, 98(2), 310-357

Cordes, C. L., \& Dougherty, T. W. (1993). A review and an integration of research on job burnout. Academy of management review, 18(4), 621-656. 
Cordes, C. L., \& Dougherty, T. W. (1993). A review and an integration of research on job burnout. Academy of management review, 18(4), 621-656.

Crawford, E. R., LePine, J. A., \& Rich, B. L. (2010). Linking job demands and resources to employee engagement and burnout: a theoretical extension and meta-analytic test. Journal of Applied Psychology, 843-848

Crawford, E. R., LePine, J. A., \& Rich, B. L. (2010). Linking job demands and resources to employee engagement and burnout: a theoretical extension and meta-analytic test. Journal of Applied Psychology, 95(5), 834-848

Demerouti, E., Bakker, A. B., Nachreiner, F., \& Schaufeli, W. B. (2001). The job demands-resources model of burnout. Journal of Applied psychology, 86(3), 499-512

Ducharme, L. J., Knudsen, H. K., \& Roman, P. M. (2007). Emotional exhaustion and turnover intention in human service occupations: The protective role of coworker support. Sociological Spectrum, 28(1), 81-104.

Dysvik, A., \& Kuvaas, B. (2013). Intrinsic and extrinsic motivation as predictors of work effort: The moderating role of achievement goals. British Journal of Social Psychology, 52(3), 412-430.

Eisenberger, R., Stinglhamber, F., Vandenberghe, C., Sucharski, I. L., \& Rhoades, L. (2002). Perceived supervisor support: Contributions to perceived organizational support and employee retention. Journal of applied psychology, 87(3), 565-573

Ellinger, A. D., Ellinger, A. E., \& Keller, S. B. (2003). Supervisory coaching behavior, employee satisfaction, and warehouse employee performance: A dyadic perspective in the distribution industry. Human Resource Development Quarterly, 14(4), 435-458.

Fisher, C. D. (1985). Social support and adjustment to work: A longitudinal study. Journal of management, 11(3), 39-53.

Greenglass, E. R., Burke, R. J., \& Konarski, R. (1997). The impact of social support on the development of burnout in teachers: Examination of a model. Work \& Stress, 11(3), 267-278.

Griffeth, R. W., Hom, P. W., \& Gaertner, S. (2000). A meta-analysis of antecedents and correlates of employee turnover: Update, moderator tests, and research implications for the next millennium. Journal of management, 26(3), 463488. 
Guchait, P., Paşamehmetoğlu, A., \& Dawson, M. (2014). Perceived supervisor and co-worker support for error management: Impact on perceived psychological safety and service recovery performance. International Journal of Hospitality Management, 41, 28-37.

Harter, J. K., Schmidt, F. L., \& Hayes, T. L. (2002). Business-unit-level relationship between employee satisfaction, employee engagement, and business outcomes: a meta-analysis, Journal of Applied Psychology, 87(2), 268-279

Hobfoll, S. E. (1989). Conservation of resources: A new attempt at conceptualizing stress. American psychologist, 44(3), 513-524

Hobfoll, S. E., \& Freedy, J. (1993). Conservation of resources: A general stress theory applied to burnout.

Joiner, T. A. (2007). Total quality management and performance: The role of organization support and co-worker support. International Journal of Quality \& Reliability Management, 24(6), 617-627.

Karatepe, O. M. (2010). The effect of positive and negative work-family interaction on exhaustion: does work social support make a difference?. International Journal of Contemporary Hospitality Management, 22(6), 836-856.

Karatepe, O. M., Keshavarz, S., \& Nejati, S. (2010). Do core self-evaluations mediate the effect of coworker support on work engagement? A study of hotel employees in Iran. Journal of Hospitality and Tourism Management, 17(01), 62-71.

Kossek, E. E., Pichler, S., Bodner, T., \& Hammer, L. B. (2011). Workplace social support and work-family conflict: A meta-analysis clarifying the influence of general and work-family-specific supervisor and organizational support. Personnel psychology, 64(2), 289-313.

Kuvaas, B., \& Dysvik, A. (2010). Exploring alternative relationships between perceived investment in employee development, perceived supervisor support and employee outcomes. Human Resource Management Journal, 20(2), 138-156.

Lee, R. T., \& Ashforth, B. E. (1996). A meta-analytic examination of the correlates of the three dimensions of job burnout. Journal of Applied Psychology, 81(2), 123-133 
Li, F., Jiang, L., Yao, X., \& Li, Y. (2013). Job demands, job resources and safety outcomes: The roles of emotional exhaustion and safety compliance. Accident Analysis \& Prevention, 51, 243-251.

Lichtenstein, R., Alexander, J. A., McCarthy, J. F., \& Wells, R. (2004). Status Differences in Cross-Functional Teams: Effects on Individual Member Participation, Job Satisfaction, and Intent to Quit*. Journal of Health and Social Behavior, 45(3), 322-335

Maslach, C., \& Goldberg, J. (1998). Prevention of burnout: New perspectives. Applied and preventive psychology, 7(1), 63-74.

Maslach, C., \& Jackson, S. E. (1981). MBI: Maslach burnout inventory. Palo Alto, CA, 1(2), 49-78.

Maslach, C., \& Leiter, M. P. (1997). The truth about burnout.

Maslach, C., Jackson, S. E., \& Leiter, M. P. (1986). Maslach Burnout Inventory. Palo Alto.

Maslach, C., Schaufeli, W. B., \& Leiter, M. P. (2001). Job burnout. Annual review of psychology, 52(1), 397-422.

Mayo, M., Sanchez, J. I., Pastor, J. C., \& Rodriguez, A. (2012). Supervisor and coworker support: a source congruence approach to buffering role conflict and physical stressors. The International Journal of Human Resource Management, 23(18), 3872-3889.

McCalister, K. T., Dolbier, C. L., Webster, J. A., Mallon, M. W., \& Steinhardt, M. A. (2006). Hardiness and support at work as predictors of work stress and job satisfaction. American Journal of Health Promotion, 20(3), 183-191.

Morgeson, F. P., \& Humphrey, S. E. (2006). The Work Design Questionnaire (WDQ): developing and validating a comprehensive measure for assessing job design and the nature of work. Journal of applied psychology, 91(6), 1321-1339

Muhammad, A. H., \& Hamdy, H. I. (2005). Burnout, supervisory support, and work outcomes: a study from an Arabic cultural perspective. International Journal of Commerce and Management, 15(3/4), 230-243. 
Nahrgang, J. D., Morgeson, F. P., \& Hofmann, D. A. (2011). Safety at work: a meta-analytic investigation of the link between job demands, job resources, burnout, engagement, and safety outcomes. Journal of Applied Psychology, $1-24$

Ng, T. W., \& Sorensen, K. L. (2008). Toward a further understanding of the relationships between perceptions of support and work attitudes: A metaanalysis. Group \& Organization Management, 33(3), 243-268.

O'Driscoll, M. P., \& Beehr, T. A. (1994). Supervisor behaviors, role stressors and uncertainty as predictors of personal outcomes for subordinates. Journal of organizational Behavior, 15(2), 141-155

Rhoades, L., \& Eisenberger, R. (2002). Perceived organizational support: a review of the literature. Journal of Applied Psychology, 87(4), 698-714

Rich, B. L., Lepine, J. A., \& Crawford, E. R. (2010). Job engagement: Antecedents and effects on job performance. Academy of management journal, 53(3), 617-635.

Richardsen, A. M., \& Burke, R. J. (1993). Occupational stress and work satisfaction among Canadian women physicians. Psychological Reports, 72(3), 811-821.

Rousseau, V., Salek, S., Aubé, C., \& Morin, E. M. (2009). Distributive justice, procedural justice, and psychological distress: the moderating effect of coworker support and work autonomy. Journal of Occupational Health Psychology, 14(3), 305-317

Ru Hsu, Y. (2011). Work-family conflict and job satisfaction in stressful working environments: The moderating roles of perceived supervisor support and internal locus of control. International Journal of Manpower, 32(2), 233248.

Russo, M., Shteigman, A., \& Carmeli, A. (2016). Workplace and family support and work-life balance: Implications for individual psychological availability and energy at work. The Journal of Positive Psychology, 11(2), 173-188.

Saks, A. M. (2006). Antecedents and consequences of employee engagement. Journal of managerial psychology, 21(7), 600-619.

Schaufeli, W. B. Maslach. C. y Marek, T.(Eds., 1993). Professional burnout: Recent developments in theory and research. 
Schaufeli, W. B., \& Bakker, A. B. (2004). Job demands, job resources, and their relationship with burnout and engagement: A multi-sample study. Journal of organizational Behavior, 25(3), 293-315.

Schaufeli, W. B., \& Bakker, A. B. (2004). Job demands, job resources, and their relationship with burnout and engagement: A multi-sample study. Journal of organizational Behavior, 25(3), 293-315.

Schaufeli, W. B., Bakker, A. B., \& Van Rhenen, W. (2009). How changes in job demands and resources predict burnout, work engagement, and sickness absenteeism. Journal of Organizational behavior, 30(7), 893-917.

Schaufeli, W. B., Maslach, C., \& Marek, T. (1993). Historical and conceptual development of burnout. Professional burnout: Recent developments in theory and research, 1-16.

Schaufeli, W. B., Salanova, M., González-Romá, V., \& Bakker, A. B. (2002). The measurement of engagement and burnout: A two sample confirmatory factor analytic approach. Journal of Happiness studies, 3(1), 71-92.

Schaufeli, W. M., \& Maslach, C. C. \& Marek, T.(1993). Professional Burnout: Recent Developments in Theory and Research.

Singh, J. (2000). Performance productivity and quality of frontline employees in service organizations. Journal of Marketing, 64(2), 15-34.

Susskind, A. M., Kacmar, K. M., \& Borchgrevink, C. P. (2003). Customer service providers' attitudes relating to customer service and customer satisfaction in the customer-server exchange. Journal of Applied Psychology, 88(1), 179.

Thanacoody, P. R., Bartram, T., \& Casimir, G. (2009). The effects of burnout and supervisory social support on the relationship between work-family conflict and intention to leave: A study of Australian cancer workers. Journal of Health, Organisation and Management, 23(1), 53-69.

Turner, N., Chmiel, N., Hershcovis, M. S., \& Walls, M. (2010). Life on the line: Job demands, perceived co-worker support for safety, and hazardous work events. Journal of occupational health psychology, 15(4), 482-493. 